\title{
The Evolution of Irish Studies at Concordia University Montreal
}

\author{
Michael Kenneally \\ Concordia University, Montreal, Canada
}

Copyright (c) 2018 by Michael Kenneally. This text may be archived and redistributed both in electronic form and in hard copy, provided that the author and journal are properly cited and no fee is charged for access.

Beginning as a modest academic initiative at Concordia University in the early 1990s, the courses and programmes in Irish Studies have developed significantly in the intervening years, resulting in the creation of a School of Irish Studies which now offers a Major in Irish Studies within the BA degree. While distinct institutional imperatives and curriculum requirements will always determine academic practices in other locations, our experience may be instructive for Irish Studies initiatives elsewhere, whether planned or already launched.

The trajectory of Irish Studies at Concordia has been a function of two key stimuli. One has been the commitment to move Irish Studies beyond its usual concentration of humanities-based fields. When I was invited to teach the Irish literature courses beginning in 1991 - as a part-time professor from an external academic institution - my conceptualization of Irish Studies was heavily weighted towards literature and history, augmented by subjects such as language, film, and music. Consequently, the Irish Studies presence began at Concordia in 1991 with courses on The Irish Literary Revival and History of Ireland, offered respectively in the English and History Departments, and funded by the St. Patrick's Society of Montreal. However, as course offerings expanded, this conceptualization of what Irish Studies entailed was transformed for several reasons. The most notable was the influence of my wife, Dr. Rhona Richman Kenneally, who from the beginning was an equal partner in the development of Irish Studies and later became the Co-founder and a Fellow of the School of Irish Studies. Her unique academic training - degrees in literature, history, architecture and design - as well as her own research in Irish Studies were crucial factors in transforming our unfolding approach. Whereas courses in film, theatre, music, language, folklore, and politics would constitute an impressive multidisciplinary approach to Irish Studies, Rhona's interest in subjects such as cultural geography, material culture, design, performance studies, space studies, and food studies markedly influenced how Irish Studies at Concordia evolved.

The second stimulus for the growth of Irish Studies at Concordia was enthusiastic student interest. Because enrolment in the aforementioned courses in English and History was robust, additional courses were gradually added in these disciplines, and then in others so that, by the early 2000's, courses in Irish film, theatre, cultural geography, music, economics, and language followed. Moreover, several externally funded courses were taught during summer sessions by visiting professors from Ireland. Such expansion notwithstanding, it was becoming evident that if Irish Studies were to be a viable discipline capable of delivering permanent programmes, a new strategy would be required. 
Instrumental to the success of the expansion of Irish studies has been our strong and ongoing engagement with the Irish community in Montreal, the Province of Quebec, and indeed Canada. Member of the Irish community were first attracted to Irish Studies through our Public Lecture Series, launched in 1991 with the support of the St. Patrick's Society. The community includes a significant group of members - many of whom, removed from their Irish roots by three or four generations - with long-standing dedication to facilitating and supporting Irish social and commemorative activities. Others community members are Irishborn immigrants who actively participate in cultural, sports or business associations. All proudly express their Irishness through a series of local events and locally derived rituals. From the beginning of Irish Studies, members of the community and major Irish organizations in Montreal begin to demonstrate their support, whether as audiences for the public lectures or other activities held under the auspices of Irish Studies. In response, they became enthused at the prospect of establishing Irish Studies as a formal academic presence at Concordia, one that would foster teaching and research whether on the history of the Irish in various regions of Canada, or courses on Irish literature, film, music and theatre that explored historical and contemporary expressions of identity. An academic program that would encompass these subjects appealed to all community members, who then began to work assiduously to achieve this goal.

The story of setting up the Canadian Irish Studies Foundation is a far too complicated narrative to present here. What should be noted, however, is the enthusiasm of community members such as Peter O'Brien and Brian O'Neill Gallery in soliciting support from many individuals, foundations, and companies, as well as the governments of Quebec, Canada, and Ireland.

As funds became available, additional courses were offered, including on the history of the Irish in Montreal, in Quebec, and in Canada. By 2002, the pro-active and committed partnership of Concordia lead to several significant milestones: a Minor in Irish Studies was approved; the Centre for Irish Studies was created; and the University partnered with the Foundation to establish a Research Chair in Canadian Irish Studies. Having been chosen for this position, and appointed Director of the Centre, I moved full-time to Concordia and began teaching a rotating selection of courses in Irish literature. In 2004, the Peter O'Brien Visiting Scholar was inaugurated, jointly funded by Concordia and the Foundation. Annually, this position brought distinguished scholars, usually from Ireland, to teach courses that helped to expand our curriculum.

From 2002 to 2009, with an increasing enthusiastic student response, it was evident that a different academic structure was required to facilitate growth. Accordingly, in 2009, Concordia University created the School of Irish Studies, a separate department capable of creating unique programs and hiring its own professors. I was appointed Principal of the School, and, within several years, new professors were hired in history, literature, diaspora studies, performance studies, and ethnomusicology, the latter an appointment to the Johnson Research Chair in Quebec and Canadian Irish Studies. Concordia University and the Government of Quebec jointly funded this latter position. Later, a Junior Scholar in the Irish Language, funded through a partnership with the Ireland Canada University Foundation and the School, was appointed annually to teach language courses. All these positions made possible regular and diverse course offerings within a growing multidisciplinary framework.

By far the most pivotal development occurred in 2012 when Quebec's Department of Education gave approval for Concordia University to offer a stand-alone Bachelor of Arts degree in Irish Studies. A degree-granting program focusing on Ireland and its diaspora, housed in a separate department, was the culmination of more than twenty years of building Irish Studies, and was the result of a unique partnership between Concordia University, the Montreal Irish community, and the Governments of Quebec, Canada and Ireland. 
Even though the majority of our students had no Irish background, they were attracted to the exploration of Ireland's literature, music, dance and folklore, and its complex history of two evolving linguistic, religious, social and culture traditions, the study of which offered interdisciplinary engagements with a broad range of issues that ultimately transcended Irish matters. While these wider implications were inherent in most courses, in some instances they were more overt. For example, "Rebellions in Ireland and Quebec: 1798 and 1837", a history course comparing two shaping moments in emerging national identities, has been extremely popular. In the current academic year, "Nationalism and Unionism in Scotland and Ireland" is another manifestation of the rich potential when the lens of Irish Studies is adjusted to a larger focus. Courses to be taught by visiting professors in summer 2018 are: "An Introduction to Irish Visual, Material, and Design Culture", "The Irish Economy and the European Union", and "Contemporary Irish Fiction and the Irish Landscape".

The attractiveness of multidisciplinary programmes that emphasize the comparative and interdisciplinary possibilities of Irish Studies has also been underscored for us by the rapid increase in graduate students. Currently, Concordia has two dozen graduate students, evenly divided between the $\mathrm{MA}$ and $\mathrm{PhD}$, some in single disciplines such as history or literature, others in interdisciplinary speciality programmes. Research topics include:

MA: "Basque-Irish Nationalism: A Comparative Study"; "Living Vikings: Dublin's Past and Present"; "Gendering Bodies: Violence as Performance in Ireland's War of Independence (1919-1921)”; “Defining Their Own 'Irishness' Through Performance: Comparing the Montreal and Irish Parades in the Nineteenth Century"; "Food and Identity in the Irish Landscape".

PhD: "Archipelago Soundscape: Irish Music History and Vernacular Fiddle Cultures in Prince Edward Island"; "Irish Catholicism and Canadian National Identity"; "The Definition of Citizenship and Nation in Ireland and Quebec After the Act of Union Daniel O'Connell and Louis-Joseph Papineau as Case Studies"; "Complicating Meaning in Materials: Irish Lace in Portraits of Queen Victoria"; "Media Infrastructure, Built Space, and Financialization in Post-Crisis Ireland"; and several literary topics on authors such as Joyce, Beckett and Flann O’Brien.

The broad-based conceptualization that defines Irish Studies at Concordia has been reinforced further through the presence of the Canadian Journal of Irish Studies, edited by Rhona Richman Kenneally. Her understanding of Irish Studies as a multifaceted scholarly domain is a vision that challenges conventional practices. The intellectual environment of the School has been immensely enriched by the innovative topics chosen in recent special numbers of CJIS: Queering Ireland (2010); Culture and "Out of Placeness" in Post-Celtic Tiger Ireland, (2011); Text and Beyond Text: New Visual, Material, and Spatial Perspectives In Irish Studies (2014); Irish Environmental Humanities (2017); and The Food Issue (Forthcoming, 2018).

With Irish Studies now anchored in one home unit, but also disbursed across the university through cross-listed courses and transdisciplinary graduate studies, we are able to offer rotating courses in academic fields such as literature, history, ethnomusicology, design, film, theatre, cultural geography, folklore, language economics, politics, women's studies, religion, materiality and spatiality, performance studies, memory studies, and food studies. By engaging with such subjects, often from an interdisciplinary perspective, students come to recognize that questions relating to Irish social, cultural and political matters resonate far beyond Ireland. Indeed, as our programmes have evolved, our emphasis has been that to study 
Ireland and its diaspora is to be introduced not only to a unique culture and complicated history but to engage with fundamental issues facing other social, ethnic and national groups. In our mission statement we identify some of these complex international issues, which include:

colonialism and empire; nationalism and post-colonialism; cultural nationalism and indigenous linguistic preservation; rebellion, partition and political devolution; famine, emigration and exile; diasporic settlement and integration; mass trauma, cultural memory and public commemoration; sectarianism, conflict resolution and the politics of peace and reconciliation; the role of place, landscape, home and memory in identity formation; and the shifts in national affiliation and transformation of regional economies produced by globalization.

While the accomplishments of Irish Studies at Concordia are firmly grounded in the university's unique environment and are inextricably connected with the Irish community, there may, nevertheless, be lessons for other institutions. Our experience has demonstrated that courses in a broad spectrum of disciplines, including on subjects related to an institution's immediate and national contexts, not only strike a responsive chord in students from diverse backgrounds but can reinforce the claim for Irish Studies to have a permanent place in the university curriculum.

Received: 29 January 2018

Michael Kenneally is the Principal of the School of Irish Studies at Concordia University in Montreal. He has completed three terms as inaugural holder of the Research Chair in Canadian Irish Studies. His areas of research interest are nineteenth-century Irish life writing, and modern and contemporary Irish literature. He has recently co-edited (with Margaret Kelleher) Ireland and Quebec: Multidisciplinary Perspectives on History, Culture and Society (2016), and is currently guest editing a special issue of the Canadian Journal of Irish Studies on the contemporary Irish short story. He has served as President of the Canadian Association of Irish Studies and Chair of the International Association for the Study of Irish Literatures.

Michael.Kenneally@concordia.ca 